\title{
Do intronic mutations affecting splicing of WT1 exon 9 cause Frasier syndrome?
}

\author{
Department of \\ Pathology, Keio \\ University School of \\ Medicine, 35 \\ Shinanomachi, \\ Shinjuku-ku, Tokyo \\ 160, Japan \\ H Kikuchi \\ A Takata \\ R Fukuzawa \\ J Hata
}

Department of Laboratory Medicine, Keio University, Tokyo, Japan

H Kikuchi

2nd Department of Pathology, Toho University School of Medicine, 5-21-16 Ohmorinishi, Ohta-ku, Tokyo 143, Japan Y Akasaka

Department of Paediatrics, Keio University, Tokyo, Japan

H Yoneyama

Y Kurosawa

Department of Paediatric Nephrology, Tokyo Metropolitan Kiyose Children's Hospital, 1-3-1

Umezono, Kiyose-shi, Tokyo 204, Japan

$M$ Honda

Department of Paediatrics, Saiseikai Utsunomiya Hospital, 911-1 Takebayashicho, Utsunomiya-shi, Tochigi 320, Japan

Y Kamiyama

Correspondence to: Dr Hata.

Received 2 July 1997 Revised version accepted for publication 4 September 1997

Haruhito Kikuchi, Ayako Takata, Yoshikiyo Akasaka, Ryuji Fukuzawa, Hiroshi Yoneyama, Yoshihiro Kurosawa, Masataka Honda, Yasunori Kamiyama, Jun-ichi Hata

\begin{abstract}
The WT1 gene, one of the genes responsible for Wilms tumour, is thought to play a crucial role in the development of the kidneys and gonads. This gene encodes four protein isoforms resulting from two alternative splicing sites, one of which involves inclusion or exclusion of lysine, threonine, and serine (KTS) between the third and fourth zinc finger domains. WT1 is virtually always mutationally inactivated in patients with Denys-Drash syndrome. We analysed WT1 in eight patients who had been diagnosed as having this syndrome, and identified five previously unknown mutations affecting splicing donor sites of intron 9. These mutations affect alternative splicing. The isoforms retaining KTS are not produced. The clinical features of the patients with these intronic mutations were consistent with those of Frasier syndrome, characterised by a more slowly progressive nephropathy than DenysDrash syndrome, associated streak gonads, and no Wilms tumour development. Our results indicate that WT1 isoforms, including/excluding KTS, have different functions in tumorigenesis and organogenesis of the kidneys and gonads. $(\mathcal{Y}$ Med Genet 1998;35:45-48)
\end{abstract}

Keywords: WT1 gene; Frasier syndrome; intronic mutation

Wilms tumour (nephroblastoma) is a childhood tumour arising from the developing kidney. Molecular analyses have shown a Wilms tumour suppressor gene located in chromosome band $11 \mathrm{p} 13$, which has been named WT1. ${ }^{12}$ This gene encodes proteins with four $\mathrm{Cys}_{2}-\mathrm{His}_{2}$ zinc fingers and a proline/ glutamine rich amino terminus. ${ }^{12}$ There are four WT1 protein isoforms resulting from two alternative splice sites. ${ }^{3}$ The first site involves the presence or absence of 17 amino acids encoded by exon 5 , while the second involves inclusion or exclusion of three amino acids, lysine, threonine, and serine (KTS), between the third and fourth zinc finger domains. In northern blot analysis ${ }^{12}$ and in situ hybridisation studies, ${ }^{45}$ this gene is expressed in only a limited number of tissues, such as the fetal kidneys and gonads. As to pathological conditions, there are several Wilms tumour anomaly complex syndromes caused by mutations of the WT1 gene. Therefore, the WT1 gene is thought to play a crucial role in the development of these organs. Dysfunction of the gene leads to both Wilms tumorigenesis and urogenital abnormalities. Denys-Drash syndrome, one such disorder, is characterised by renal failure, Wilms tumour, and intersex abnormalities. Patients with this syndrome nearly always carry point mutations in the zinc finger regions of WT1. ${ }^{6}$ The most frequent abnormality is a $C$ to $T$ transition in exon 9 , converting ${ }^{394} \mathrm{Arg}$ to Trp. Although most other mutations are also exonic, three cases with mutations in the splicing donor site of intron 9 have been reported..$^{7-9}$

We analysed the genomic DNA of patients diagnosed as having Denys-Drash syndrome and identified novel splicing donor site mutations of WT1. These mutations affected alternative splicing, such that isoforms retaining KTS could not be produced. The clinical features of patients with the intronic mutations correspond to those of Frasier syndrome, which has been proposed by Moorthy et $a l^{10}$ to be related to but distinct from Denys-Drash syndrome. Frasier syndrome is characterised by a more slowly progressive nephropathy, streak gonads, and no Wilms tumour development. Our results indicate that imbalance of

Table 1 Clinical picture and genotype

\begin{tabular}{|c|c|c|c|c|c|c|}
\hline \multirow[b]{2}{*}{ Cases } & \multirow[b]{2}{*}{ Age (y) } & \multicolumn{3}{|l|}{ Nephropathy } & \multirow[b]{2}{*}{ Genotype/phenotype } & \multirow[b]{2}{*}{ Tumours } \\
\hline & & Proteinuria & Course (dialysis) & Histology & & \\
\hline E-1 & 1 & & From $1 \mathrm{y}$ & FGS with mesangial sclerosis & $46, \mathrm{XX} /$ normal & Wilms tumour \\
\hline $\mathrm{E}-2$ & 22 & Unclear & From $2 \mathrm{y}$ & FGS & $\begin{array}{l}46, X Y / \text { female external genitalia, } \\
\text { streak gonad }\end{array}$ & \\
\hline E-3 & 5 & Unclear & From $1 \mathrm{mth}$ & & $46, \mathrm{XX} /$ normal & Wilms tumour \\
\hline I. $1^{\star}$ & 18 & $3 y$ & Not performed & FGS & $\begin{array}{l}46, X Y / \text { female external genitalia, } \\
\text { streak gonad }\end{array}$ & 一 \\
\hline I. $2^{\star}$ & 18 & $3 y$ & Not necessary at present & FGS & $\begin{array}{l}46, X Y / \text { female external genitalia, } \\
\text { streak gonad }\end{array}$ & - \\
\hline 1.3 & 19 & $5 y$ & From 16 y & FGS & $\begin{array}{l}46, X Y / \text { female external genitalia, } \\
\text { streak gonad }\end{array}$ & Gonadoblastoma \\
\hline I.4 & 3 & $3 y$ & Reserved renal function & & 46,XY/female external genitalia & - \\
\hline I.5 & 26 & $6 y$ & From 23 y & FGS & $\begin{array}{l}46, X Y / \text { female external genitalia, } \\
\text { streak gonad }\end{array}$ & 一 \\
\hline
\end{tabular}

\footnotetext{
${ }^{\star}$ Cases I.1 and I.2 are identical twins. FGS: focal glomerular sclerosis.
} 
Table 2 WT1 mutations

\begin{tabular}{llll}
\hline Cases & Exon/intron & DNA & Amino acid \\
\hline E-1 & Exon 8 (1064) & CAGTGTGAC to CAGTATGAC & ${ }^{355}$ Cys to ${ }^{355} \mathrm{Thr}$ \\
E-2 & Exon 9 (1154) & CAGCGTAAA to CAGTGTAAA & ${ }^{385}$ Cys to $^{385} \mathrm{Arg}$ \\
E-3 & Exon 8 (1097) & TTTCGTTCAA to TTTCATTCAA & ${ }^{366} \mathrm{Arg}$ to ${ }^{366} \mathrm{His}$ \\
I.1,2,3 & Intron 9 $(+4)$ & gtgcg to gtgtg & \\
I.4 & Intron 9 $(+5)$ & gtgcg to gtgct & \\
I.5 & Intron 9 $(+2)$ & gtgcg to gcgcg & \\
\hline
\end{tabular}

A

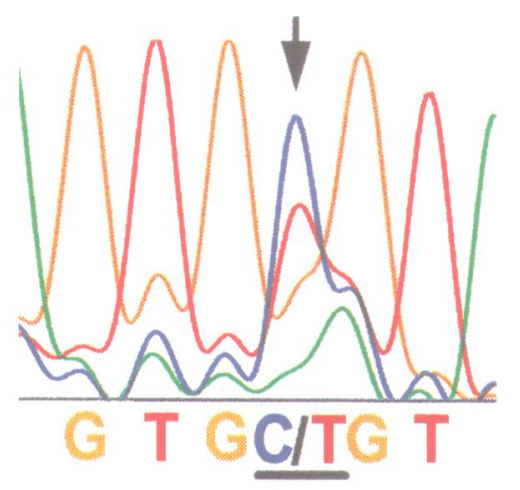

B

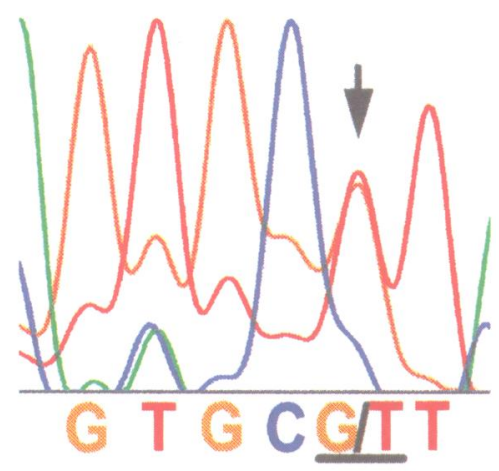

C

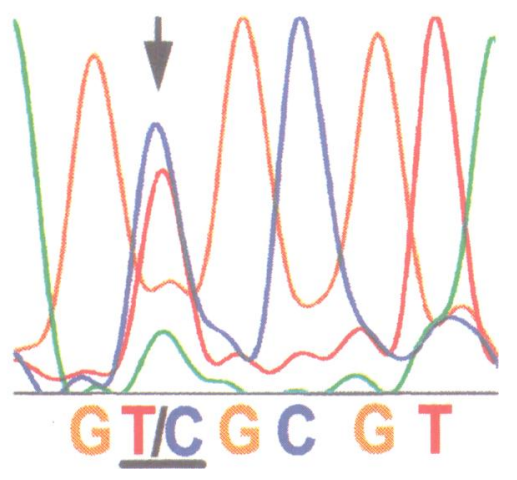

Figure 1 Direct DNA sequence analysis of the intron 9 splicing donor site of the WT1 gene from patients with intronic mutations (patients I.1, I.2, I. 3, I.4, and I.5). Sequences from $(A)$ patients I.1-3, (B) patient I.4, and (C) patient I.5. Arrows point to the mutations.

Heterozygous mutations were found at $+4(C$ to $T),+5(G$ to $T)$, and +2 ( $T$ to $C$ ) positions of intron 9 in $A, B$, and $C$, respectively.

the WT1 isoforms, caused by intronic mutations, produces symptoms and features of Frasier syndrome, and that there may be a functional difference between these isoforms in urogenital system development.

\section{Methods}

SEQUENCING ANALYSIS OF THE WT1 GENE FROM EXONS 7 TO 10

DNA was prepared from leucocytes by the SDS-proteinase $K$ method as previously described. ${ }^{11}$ WT 1 exons 7 to 10 were amplified using the following primers: 7D-S (5'GACCTACGTGAATGTTCACATG-3') and 7C-A (5'-CTTAGCAGTGTGAGAGCCTG3') for exon 7, 8-S (5'-AGATCCCCTTT TCCAGTATC-3') and 8C-A (5'-CAACA ACAAAGAGAATCA-3') for exon 8, 9C-S (5'-AAGTCAGCCTTGTGGGCCTC-3') and 9C-A (5'-TTTCCAATCCCСTCTCATCAC3') for exon 9, 10C-S (5'-CACTCGGG CCTTGATAGTTG-3') and 10C-A (5'GTCAGACTTGAAAGCAGTTC-3') for exon 10 . The cycling protocol was $94^{\circ} \mathrm{C}$ for four minutes, followed by 30 cycles of $94^{\circ} \mathrm{C}$ for one minute, $56^{\circ} \mathrm{C}$ for one minute, $72^{\circ} \mathrm{C}$ for one minute, and a final extension of $72^{\circ} \mathrm{C}$ for five minutes. PCR products were then purified on a Microspin S-400 column (Pharmacia), then analysed with a Thermo Sequenase fluorescent labelled primer cycle sequencing kit (Amersham) and ALF DNA sequencer II (Pharmacia). The fluorescent primers used for sequencing were as follows: exon 7 forward: 7-S (5'-AGCCTCCCTTCCTCTTACTC-3'), reverse: 7-A (5'-GTTTGCCCAAGACTGGA CAG-3'); exon 8 forward: 8-S (5'-AGAT CCCCTTTTCCAGTATC-3'), reverse: 8C-A (5'-AAATCAACCCTAGCCCAAGG-3'); exon 9 forward: 9B-S (5'-TAGGGCCGAGGCT AGACCTTCTCT-3'), reverse: 9C-A (5'TTTCCAATCCСTCTCATCAC-3'); exon 10 forward: 10B-S (5'-TGTGCCTGTCT CTTTGTTGC-3'), reverse: 10B-A (5'TGCTGCCTGGGACACTGAAC-3'). The results of the direct sequencing analysis were also confirmed by subcloning the PCR products into a pCR-Script $S K(+)$ cloning kit (Stratagene) and by sequencing with fluorescent T7 primer (Pharmacia).

CONSTRUCTION OF THE WT1 MINIGENES

The WT1 minigenes were constructed using a strategy similar to that of Bruening et al. ${ }^{7} \mathrm{WT} 1$ intron 9-exon 10 was amplified with DNA from normal human placenta with primers $10 \mathrm{~B}-\mathrm{S}$ and 10B-A, then subcloned into pCR-Script $S K(+)$, and the sequence was confirmed to have no mutations. Similarly, exon 9-intron 9 was amplified from genomic DNA from patients $I .1,4$, and 5 with INT-2 9B-A (5'-ATCCCTCTCATCACAATTTC ATTCC-3') and subcloned with the same kit. A normal clone and clones with each corresponding intronic mutation $(+4 \mathrm{C}$ to $\mathrm{T},+5 \mathrm{G}$ to $T$, and $+2 T$ to $C$ ) were selected after sequencing. Then an intron 9-exon $10 \mathrm{frag}$ ment restricted with $M s c \mathrm{I}$ and $\mathrm{BamHI}$ from an exon 10 clone was reinserted into normal and mutant exon 9 vectors, which were then digested with BamHI and SmaI. The constructed normal and mutant minigenes were subcloned into the $E c o$ RI site of SR $\alpha 296$, an expression vector.

RNA ISOLATION AND REVERSE TRANSCRIPTION PCR

Total RNA was extracted from transfected COS-7 cells with ISOGEN (Nippongene), then reverse transcribed by using primer $301 .^{7}$ The cDNA was then amplified under the same conditions as previously reported ${ }^{7}$ with the 


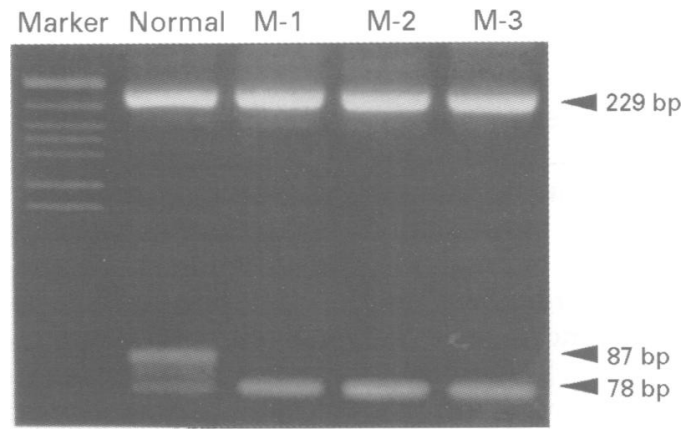

Figure 2 RT-PCR of RNA from COS-7 cells transfected with WT1 minigenes. Marker: $p B R 322 / M s p I$ digested. Normal: RT-PCR products from COS 7 cells transfected with the minigene without mutation. M1-M3: RT-PCR products from $C O S-7$ cells transfected with the ${ }^{+4} T(M-1)$, ${ }^{+5} T(M-2)$, and ${ }^{+2} C(M-3)$ minigenes. The 87 bp size fragment, which corresponds to the product containing the nine alternatively spliced nucleotides, was detected only from the normal minigene. The $229 \mathrm{bp}$ fragment was the PCR product from the input transfected vector.

exception that the number of cycles was increased from 35 to 40 and the annealing temperature was increased from $58^{\circ} \mathrm{C}$ to $60^{\circ} \mathrm{C}$. The PCR products were analysed on a $6 \%$ NuSieve GTG agarose gel (FMC).

\section{Results}

SEQUENCE ANALYSIS

We examined the eight patients whose clinical data are shown in table 1 (details of case E-1 have been reported previously). ${ }^{11}$ All had findings compatible with the criteria proposed by Habib et $a l^{12}$ for Denys-Drash syndrome. Analysis of the WT1 gene from the patients was carried out by direct sequencing of PCR products of exons 7 to 10 which encode zinc finger domains. Point mutations of the WT1 gene involving one allele were recognised in all patients except E-1, in whom the mutation was homozygous. ${ }^{11}$ Three of the mutations were exonic and five were intronic (table 2, fig 1 ).

THE INFLUENCE OF SPLICING DONOR SITE MUTATIONS ON WT1 SPLICING

Because these intronic mutations were suspected to lead to abnormal splicing, we adopted the use of a WT1 minigene, a method similar to one previously reported, ${ }^{7}$ for confirmation. Four minigene inserts, one normal and three mutant intronic sequences detected in the patients, were made and inserted into an expression vector. COS-7 cells were transfected with these constructs and the transcripts were then analysed by RT-PCR. Only one amplified product that corresponded to the transcript without nine nucleotides was obtained from the mutant minigenes, whereas two products (with or without nine bases) were obtained from the normal constructs (fig 2). The intronic mutations affecting alternative splicing between exons 9 and 10 prevent production of the transcripts with nine nucleotides.

\section{Discussion}

Mutations at the splicing donor site of intron 9 have been reported. ${ }^{7-9}$ However, the WT1 mutations at the +2 and +4 positions and the guanine to thymine transversion at the +5 position of the intron presented here have not been reported previously. The minigene assay provided in vitro confirmation that all of these mutations affect post-transcriptional processing of RNA, preventing production of the splicing variant with nine bases. This suggested that imbalance of the alternative splicing isoforms of WT1 is involved in the pathogenesis of the disease in our patients.

When the clinical features of our patients with intronic mutations and those of patients described in previous reports are compared, patients CS, JA, and VM described by Bruening et $a l,^{7}$ König et $a l_{,}{ }^{8}$ and Bardeesy et $a l{ }^{9}$ respectively, were recognised as having clinical features deviating from those of typical DenysDrash patients. These clinical features were highly consistent with those of Frasier syndrome, proposed by Moorthy et $a l^{10}$ as a disorder distinct from Denys-Drash syndrome. ${ }^{10}$ The onset of nephropathy is very early in Denys-Drash syndrome, usually in the first year of life, progressing to end stage renal failure by 3 years of age. ${ }^{1}$ On the other hand, in Frasier syndrome, the onset is at 4 years or older and the clinical course is slowly progressive, requiring at least two years to reach end stage renal failure. In our cases, nephropathy was first recognised at 3 to 6 years of age, and dialysis was not necessary until 18 years of age. In patient JA of König et $a l,{ }^{8}$ renal insufficiency was apparent at approximately 2 years of age and dialysis was started at 8 years of age. Moreover, the histological findings of renal biopsy in our patients I.1, I.2, I.3, and I.5 and in patient CS of Bruening et al were described as glomerular sclerosis (data not shown). This is not the mesangial sclerosis seen in typical Denys-Drash syndrome, ${ }^{12}$ but rather is consistent with the renal biopsy findings of the two patients studied by Moorthy et al..$^{10}$ Regarding intersex disorders, gonadal dysgenesis in patients with Denys-Drash syndrome is highly variable. ${ }^{12-14}$ In contrast, patients with intronic mutations had uniform genital malformations. Their external genitalia were female despite a 46,XY karyotype. Moreover, in our patients I.1, I.2, I.3, and I.5, as well as in CS and JA, the internal genitalia consisted of streak gonads which is characteristic of Frasier syndrome. Lastly, as regards Wilms tumorigenesis, none of our patients or those reported to have intron 9 splicing donor site mutations had developed Wilms tumour. This is in contrast to a Wilms tumour incidence of $55 \%$ among patients with Denys-Drash syndrome, as described in a comprehensive review. ${ }^{15}$ This absence of Wilms tumour development is one of the major criteria for Frasier syndrome. In summary, patients with mutations of the WT1 gene intron 9 splicing donor site showed identical characteristics which were entirely consistent with Frasier syndrome. Among our cases, patient E-2 required early initiation of dialysis from the age of 2 , although his renal histology showed focal glomerular sclerosis and he had not developed Wilms tumour by 22 years of age. Therefore, we considered him to have DenysDrash syndrome. 
In terms of pathogenesis, both Denys-Drash syndrome and Frasier syndrome are caused by specific mutations of the same gene, WT1. If the mutations occur in particular exon regions, the outcome is Denys-Drash syndrome, while mutations in the splicing donor site of intron 9 cause a series of common abnormalities defined as Frasier syndrome. Consequently, Frasier syndrome should be regarded as a distinct variant of Denys-Drash syndrome rather than a separate disease entity.

In this study, all of the patients with intronic mutations were $46, \mathrm{XY}$ females although the same mutations can be theoretically expected to occur in cases with a $46, \mathrm{XX}$ karyotype as well. This is probably because in $46, \mathrm{XX}$ patients, the diagnosis of Denys-Drash (or Frasier) syndrome is very often difficult as the malformations observed in the external genitalia are usually mild in these cases. ${ }^{13}$ Accordingly, the patients with these intronic mutations may comprise a portion of patients who clinically suffer from nephropathy of unknown aetiology. Thus, it is important to examine the genitalia of such patients and to detect mutations of the WT1 gene to gain insight into the molecular mechanism caused by the splicing donor site mutations of WT1 intron 9.

Mutations of WT1 exons 7 to 10 were previously examined in three patients with Frasier syndrome. ${ }^{16}$ However, no mutations affecting these exons could be found. This suggests that there may be diverse mechanisms producing this disorder. These patients might, however, have had mutations in the WT1 intron 9 splicing donor site, though no information was provided as to whether or not the position was normal.

It is thought that in patients with DenysDrash syndrome, specific alterations of the WT1 gene produce proteins which act in a dominant negative manner, resulting in inactivation of the product from the normal allele. In contrast, in our patients with intronic mutations, only normal products are present. A normal quantity of WT1 isoforms without KTS is produced, but the quantity of isoforms with KTS is insufficient because of the intronic mutations. Consequently, an imbalance in the ratio of +KTS/-KTS isoforms, presumably half normal versus normal, is thought to produce the characteristic clinical picture known as Frasier syndrome.

A recent study of the subnuclear localisation of these WT1 isoforms showed different localisations. The +KTS WT1 proteins are localised mainly with splicing factors and appear to be involved in post-transcriptional RNA processing, whereas -KTS forms are in the transcriptional factor domains and are thus likely to bind DNA. ${ }^{17}$ Therefore, it is possible that WT1 proteins produced by alternative splicing of exon 9 have different functions in the development of different organs and in tumorigenesis, and that this difference might explain the characteristic features of Frasier syndrome. Because the $-\mathrm{KTS}$ isoforms usually bind to genes related to growth with higher affinity, ${ }^{18}{ }^{19}$ loss of the functions of these isoforms may be more closely related to the development of Wilms tumour. On the other hand, both +KTS and -KTS may be necessary for renal organogenesis and +KTS isoforms appear to play a key role in the development of gonadal tissues. Confirmation of this hypothesis requires further study of the precise functions of both WT1 alternative splicing products, especially in developing kidneys and gonads.

The results reported here have shown that intronic mutations lead to Frasier syndrome, and provide the first clue that WT1 isoforms resulting from alternative splicing of exon 9 have different physiological roles in tumorigenesis and urogenital organogenesis.

The authors are grateful to Dr Hiroshi Horie (Chiba Children's Hospital) for providing materials. This work was supported by a Grant-in-Aid for Scientific Research from the Ministry of Education (08670216 to HK, 08457066 to $\mathrm{JH}$ ), the Entrustment of Research Program of the Foundation for Promotion of Cancer Research of Japan (2nd Term Comprehensive 10 Years Strategy for Cancer Control), a Grant-in-Aid for Paediatric Research (6-5) from the Ministry of Health and Welfare, by Keio Univerity Special Grant-in-Aid for Innovative Collaborative Research Projects, and National Grant-in-Aid for the Establishment of High-Tech Research Center in a Private University.

1 Call $\mathrm{KM}$, Glaser T, Ito CY, et al. Isolation and characterization of a zinc finger polypeptide gene at the human chromosome 11 Wilms' tumor locus. Cell 1990,60:509-20.

2 Gessler M, Poustka A, Cavenee W, Neve RL, Orkin SH, Bruns GAP. Homozygous deletion in Wilms tumours of a zinc-finger gene identified by chromosome jumping. Nature 1990;343:774-8

3 Haber DA, Sohn RL, Buckler AJ, Pelletier H, Call KM, Housman DE. Alternative splicing and genomic structure of the Wilms tumor gene WT1. Proc Natl Acad Sci USA 1991;88:9618-22.

4 Pritchard-Jones K, Fleming S, Davidson D, et al. The candidate Wilms' tumour gene is involved in genitourinary date Wilms' tumour gene is involved
development. Nature 1990;346:194-7.

5 Pritchard-Jones $\mathrm{K}$, Fleming $\mathrm{S}$. Cell types expressing the Pritchard-Jones K, Fleming S. Cell types expressing the tions for tumour histogenesis. Oncogene 1991;6:2211-20.

6 Pelletier J, Bruening W, Kashtan CE, et al. Germline mutations in the Wilms' tumor suppressor gene are associated with abnormal urogenital development in Denys-Drash syndrome. Cell 1991;67:437-47.

7 Bruening W, Bardeesy N, Silverman BL, et al. Germline intronic and exonic mutations in the Wilms' tumour gene (WT1) affecting urogenital development. Nat Genet 1992; 1:144-8.

8 König A, Jakubiczka S, Wieacker P, Schlösser HW, Gessler $M$. Further evidence that imbalance of $W T 1$ isoforms may be involved in Denys-Drash syndrome. Hum Mol Genet 1993;2:1967-8.

9 Bardeesy N, Zabel B, Schmitt K, Pelletier J. WT1 mutations associated with incomplete Denys-Drash syndrome define a domain predicted to behave in a dominant-negative fasha domain predicted to behave

10 Moorthy AV, Chesney RW, Lubinsky M. Chronic renal failure and XY gonadal dysgenesis: "Frasier" syndrome - a commentary on reported cases. Am $\mathcal{F}$ Med Genet Suppl 1987;3:297-302

11 Kikuchi H, Akasaka Y, Kurosawa Y, Yoneyama H, Kato S, Hata J. A critical mutation in both WT1 alleles is not sufficient to cause Wilms' tumor. FEBS Lett 1995;360:26-8. 12 Habib R, Loirat C, Gubler MC, et al. The nephropathy,
associated with male pseudohermaphroditism and Wilms' tumor (Drash syndrome): a distinctive glomerular lesion report of 10 cases. Clin Nephrol 1985;24:269-78.

13 Coppes MJ, Huff V, Pelletier J. Denys-Drash syndrome: relating a clinical disorder to genetic alterations in the
tumor suppressor gene WT1. F Pediatr 1993;123:673-8.

14 Mueller RF. The Denys-Drash syndrome. $\mathcal{F}$ Med Genet 1994;31:471-7.

15 Eddy AA, Mauer SM. Pseudohermaphroditism, glomerulopathy, and Wilms tumor (Drash syndrome): frequency in lopathy, and Wilms tumor (Drash syndrome): fre.

16 Poulat F, Morin D, König A, et al. Distinct molecular origins Poulat F, Morin D, König A, et al. Distinct molecular origins 91:285-6.

17 Larsson SH, Charlieu J, Miyagawa K, et al. Subnuclear localization of WT1 in splicing or transcription factor domains is regulated by alternative splicing. Cell 1995;81 391-401.

18 Drummond IA, Madden SL, Rohwer-Nutter P, Bell GI, Sukhatme VP, Rauscher FJ III. Repression of the insulin-like growth factor II gene by the Wilms tumor suppressor WT1. Science 1992;257:674-8.

19 Rauscher FJ III; Morris JF, Tournary OE, Cook DM, Curran T. Binding of the Wilms' tumor locus zinc finger protein to the EGR-1 consensus sequence. Science 1990;250:1259-62. 